\title{
Cefoperazone/Sulbactam-Induced Abdominal Wall Hematoma and Upper Gastrointestinal Bleeding: A Case Report and Review of the Literature
}

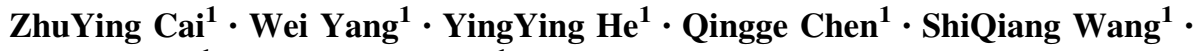 \\ Xuming Luo ${ }^{1} \cdot$ Xiongbiao Wang ${ }^{1}$
}

Published online: 18 March 2016

(c) The Author(s) 2016. This article is published with open access at Springerlink.com

\begin{abstract}
An 87-year-old woman developed abdominal wall hematoma and upper gastrointestinal bleeding during treatment with cefoperazone/sulbactam for pneumonia. The woman received cefoperazone/sulbactam at $4.5 \mathrm{~g}$ twice daily for intravenous infusion. After 7 days, she developed sudden onset of left lower abdominal pain, associated with subcutaneous mass, and vomited a coffee-colored liquid. Investigations revealed a coagulation index abnormality and activated partial thromboplastin time and prothrombin time increased obviously. She was diagnosed with cefoperazoneinduced hemorrhage. Cefoperazone/sulbactam was discontinued and the patient received vitamin K1. The blood coagulation function improved and hematoma disappeared after 3 days. A Naranjo assessment score of 6 was obtained, indicating a probable relationship between the patient's coagulation function disorder and her use of the suspect drug.
\end{abstract}

\section{Key Points}

Cefoperazone/sulbactam might induce abdominal wall hematoma.

Clinicians should be aware of the side effect even though it is very rare.

The mechanism of abnormal coagulation induced by cefoperazone is still unclear.

Z. Cai and W. Yang are the first authors who contributed equally to this work.

\section{Xiongbiao Wang}

xiongbiao6@yahoo.com

1 Department of Respiratory Medicine, Putuo Hospital, Shanghai University of Traditional Chinese Medicine, No. 164, LanXi Road, Shanghai, China

\section{Introduction}

The third-generation cephalosporin antibiotic cefoperazone has been widely used since the 1980s [1, 2]. Cefoperazone/sulbactam (Sulperazon; Pfizer Inc., China) is an antimicrobial combination including sulbactam, which can enhance the activity of enzyme-resistant antibiotics. Cefoperazone/sulbactam as a broad-spectrum antibiotic is used in cases of moderate to severe infection [3-7]. A great deal of information has accumulated regarding its possible adverse effects, including hypersensitivity vasculitis and hyponatremia [1, 8-10]. One important side effect is vitamin $\mathrm{K}$ deficiency, which can induce abnormal coagulation function and hemorrhage [11, 12]. Fortunately, this is treatable with vitamin K supplementation [13]. Over the years, this effect has fallen out of general notice because the incidence is so low. About 30 articles mentioning cefoperazone-induced hypoprothrombinemia and hemorrhage have been entered into PubMed ever. The most frequent site of bleeding was the urinary tract, and more than three-quarters of cases of bleeding from this area were microscopic. The second most frequent site was the integument, then bleeding from the nose, mouth, or pharynx, then the digestive system [14]. No cases of subcutaneous hematoma have been reported. Here, a case of abdominal wall hematoma most likely induced by cefoperazone/sulbactam is reported and cefoperazone-induced hemorrhage is reviewed.

\section{Case Report}

The patient (female, 87 years old) was hospitalized on June 16,2014 , because of yellow purulent sputum and cough with dyspnea lasting 5 days. The chest film suggested right lower 
lung infection and a small amount of pleural effusion on the right side. She had a history of chronic renal insufficiency, blood urea nitrogen was $16.1 \mathrm{mmol} / \mathrm{L}$, and creatinine was $334 \mu \mathrm{mol} / \mathrm{L}$ at the time of admission. There was no bleeding history. The pneumonia was successively treated with mezlocillin and piperacillin/tazobactam, but symptoms did not improve. The antibiotic was upgraded to cefoperazone/sulbactam $4.5 \mathrm{~g}$ twice daily intravenous infusion from June 23. The symptoms improved daily. At 4:00, June 30, the patient felt a sudden onset of left lower abdominal pain, associated with subcutaneous mass. This mass was round, $6 \times 6 \mathrm{~cm}$ in size, and hard to touch. The patient experienced tenderness with no obvious wave motion. Abdominal computed tomography (CT) showed possible hematoma at the lower left abdominal wall (Fig. 1a). Abdominal B ultrasound revealed mixed masses $(100 \times 36 \mathrm{~mm}$, smooth border, unhomogenous echo) at the left lower abdominal wall (Fig. 1b). The patient had not defecated in the past $48 \mathrm{~h}$, and incarceration of a ventral hernia was considered. Fasting, rehydration, spasmolysis, and acesodyne were implemented, but these measures did not ease the symptoms. At 17:00, June 30 , the patient vomited a coffee-colored liquid, about $200 \mathrm{~mL}$. Occult bloods test of vomit were positive. On July 1 , the patient's condition had not improved, there was no anal flatus or defecation, the abdomen was soft, and the mass still had apparent tenderness. No skin ecchymosis was observed nearby. The blood coagulation showed on July 1: prothrombin time (PT) $80 \mathrm{~s}$, partial thromboplastin time (PTT) $57.1 \mathrm{~s}$, PT international normalized ratio (INR) 7.9, fibrinogen $4.8 \mathrm{~g}$, and thrombin time $15.7 \mathrm{~s}$. At 15:30, the mass was detected under ultrasound guiding. The puncture drew $30 \mathrm{~mL}$ dark red liquid. Cefoperazone/sulbactam-induced abnormal coagulation and hematoma were considered. The drug was withdrawn and vitamin K1 $40 \mathrm{mg}$ was given to correct the coagulation disorder immediately. On July 2, abdominal pain significantly reduced and the anal exhaust restored. Blood coagulation function improved visibly (PT $13.4 \mathrm{~s}$, PTT $27.3 \mathrm{~s}$, PT INR 1.2, fibrinogen $5.45 \mathrm{~g}$, and thrombin time $15.2 \mathrm{~s}$ ). On July 3 , the coagulation function of the patient returned to normal (PT $11.9 \mathrm{~s}$, PTT $22.9 \mathrm{~s}$, PT INR 1.06, fibrinogen $5.45 \mathrm{~g}$, and thrombin time $15.7 \mathrm{~s}$ ). The symptoms had not recurred; the mass at lower left abdomen became smaller, which was confirmed by ultrasound (Fig. 1c). No other treatment was started and stopped at the same time. The patient was discharged on July 15 , at which time she showed no symptoms.

\section{Discussion}

Cefoperazone/sulbactam has good antibacterial effects against Escherichia coli, Klebsiella, Proteus, Salmonella typhi, Shigella, other Enterobacteriaceae, and
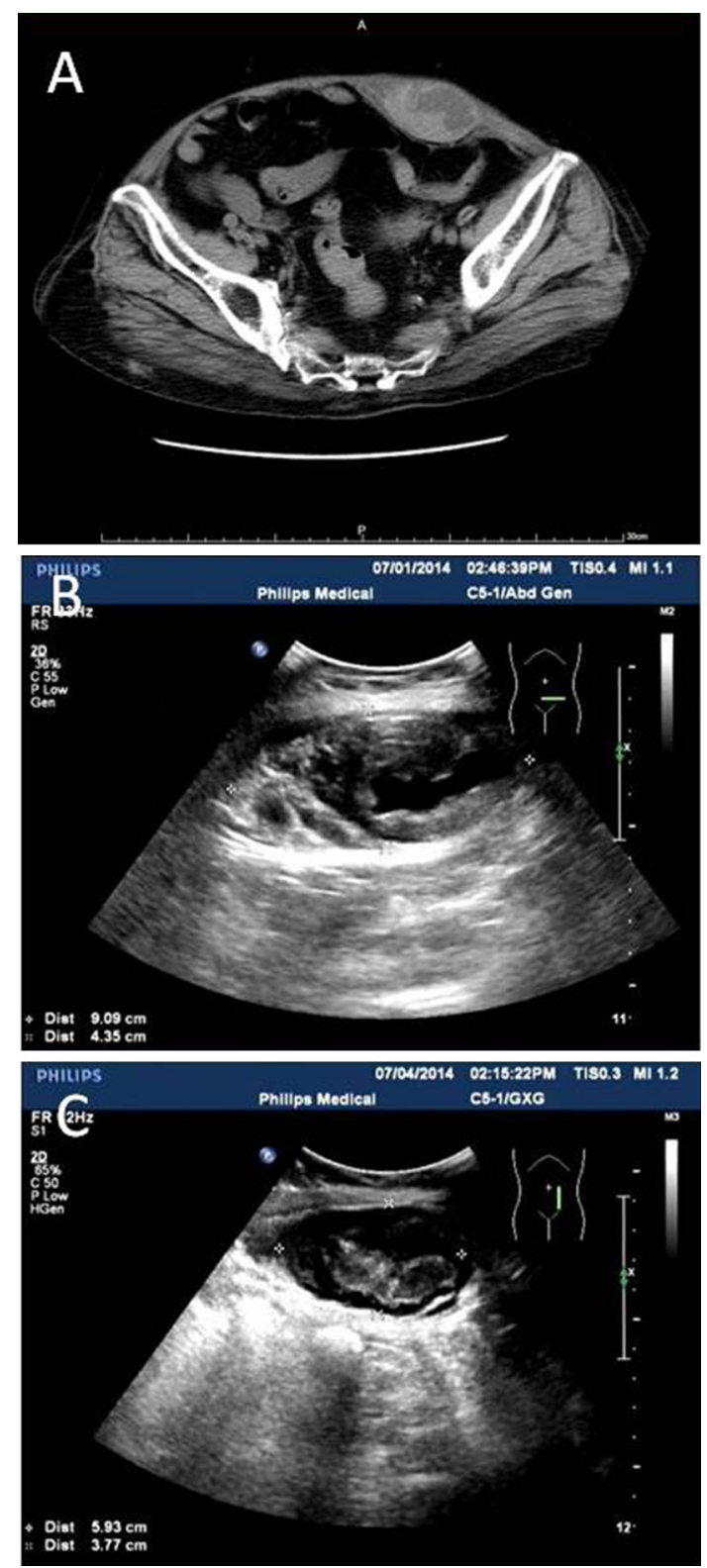

Fig. 1 a Hematoma at lower left abdominal wall was suggested by abdominal CT. b Mixed masses at left lower abdominal wall was revealed by the abdomen $\mathrm{B}$ ultrasound. $\mathbf{c}$ Absorbed hematoma by $\mathrm{B}$ ultrasound

Pseudomonas aeruginosa. The drug has been used extensively in severe infection of the respiratory system, digestive system, and genitourinary system. Most of the patients tolerated it very well. This patient had no history of abnormal coagulation function and no history of bleeding, blood system disease, or liver disease. Before administration of the drug, coagulation function was normal. No other drug may have affected coagulation function during this period. After 1 week of cefoperazone/sulbactam, the coagulation index showed abnormality and activated partial thromboplastin time (APTT) and PT increased 
obviously. Increased APTT might be induced by the deficiency of coagulation factor $\mathrm{X}$, factor $\mathrm{V}$, and prothrombin. This is commonly caused by liver disease and vitamin $\mathrm{K}$ deficiency. After withdrawal of the drug and administration of vitamin $\mathrm{K} 1$, blood coagulation function was corrected, and symptoms improved rapidly without recurrence. Other causes of the bleeding were excluded. Cefoperazone/sulbactam was inferred to be a causal factor regarding coagulation dysfunction and hemorrhage because of vitamin $\mathrm{K}$ deficiency.

There have been many reports about cefoperazone-induced hemorrhage and hypoprothrombinemia, especially before 1990 (Table 1). It seems that hypoprothrombinemia was a very common event during therapy. The incidence ranged from 4 to $68 \%$ [15], and the risk was greatest in debilitated patients with cancer, intra-abdominal infection, liver disease, and renal failure [2, 13, 15]. Hypoprothrombinemia and bleeding may be caused by vitamin $\mathrm{K}$ deficiency, as suggested by the fact that vitamin K therapy can resolve both. However, the mechanism underlying this effect is still unknown. Several mechanisms have been proposed, including eradication of gastrointestinal bacteria, direct inhibition of vitamin K-dependent coagulation, and indirect inhibition of coagulation [16]. The very high frequency of hypoprothrombinemia associated with cefoperazone in the 1990s also raised a hypothesis about the role of their N-methylthiotetrazole (NMTT) side chains. NMTT inhibits vitamin $\mathrm{K}$-dependent carboxylation in vitro. Cefoperazone has an NMTT side chain at the 3 position of the cephalosporin nucleus and so might cause hypoprothrombinemic bleeding and disulfiram-like reactions.

Vitamin $\mathrm{K}$ therapy is routinely given alongside cefoperazone in some hospitals. However, there is some question as to whether prophylactic vitamin $\mathrm{K}$ is necessary. If it is true that NMTT-containing antibiotics, such as cefoperazone, can induce hypoprothrombinemia, supplemental vitamin $\mathrm{K}$ may be necessary during therapy. However, some evidence suggests that this hypothesis may be incorrect. (1) Although NMTT inhibits vitamin $\mathrm{K}$-dependent carboxylation in vitro, other cephalosporins without NMTT also induce bleeding. (2) It is not clear whether antibiotics that contain NMTT liberate sufficient amounts of NMTT in vivo to antagonize clotting in patients [16]. (3) Trials in healthy volunteers did not demonstrate the effect [17]. (4) Normal volunteers showed in vivo NMTT production, but the order of magnitude (cefoperazone, moxalactam, and cefotetan in descending order) was different from the usual order of clinical risk. There was no NMTT-concentration-versuseffect relationship. Patients who were vitamin $\mathrm{K}$ deficient were more sensitive to lower NMTT concentrations than those with normal vitamin $\mathrm{K}$ status. In surveillance studies, NMTT-containing antibiotics were no more frequently associated with hypoprothrombinemia or bleeding than antibiotics lacking NMTT [18]. (5) Cefoperazone caused endogenous vitamin K1 2,3-epoxide in 4/5 patients, but these patients showed a statistically significant increase in endogenous plasma vitamin K levels [19]. (6) Serum concentrations were not found to be correlated with hypoprothrombinemia [20]. (7) Several clinical trials have demonstrated that NMTT antibiotics are not associated with hypoprothrombinemia. In one retrospective cohort study, 374 patients received cefoperazone from February 1983 to March 1986 at a teaching hospital. This work concluded that prophylactic vitamin $\mathrm{K}$ is probably not warranted [14]. In another retrospective study, 50 patients underwent urologic procedures and received cefoperazone for 3 days to prevent infection. This work also concluded that routine use of vitamin $\mathrm{K}$ with cefoperazone for perioperative prophylaxis of infection may not be warranted [21]. A prospective, randomized trial of 195 febrile episode in granulocytopenic patients also concluded that the use of cefoperazone was not associated with an increased incidence of hypoprothrombinemia [22]. This evidence further suggests that there is no correlation between NMTT-containing antibiotics and hypoprothrombinemia.

This report describes the first case of bleeding in our ward, though cefoperazone/sulbactam is used there very frequently for severe pulmonary infection and vitamin $\mathrm{K}$ is not prescribed. Published reports strongly suggest that in the early stage, cefoperazone and cefoperazone/sulbactam had induced hypoprothrombinemia and bleeding quite often and severely, but this response has been reported very rarely since the 1990s (Table 1). The newest clinical trial, published in 2013, revealed no bleeding in 141 patients who were not given prophylactic vitamin $\mathrm{K}$, although there were no data regarding PT [7]. One possible explanation for this phenomenon is the impurity of the products; although, this is entirely speculative, as our institution has continued to obtain the same formulation of cefoperazone/sulbactam from the same manufacturer, and there is no evidence to suggest a change in quality. High-quality products may lead to fewer and less severe side effects, including bleeding and hypoprothrombinemia. The real element responsible for the bleeding and hypoprothrombinemia may be not the cefoperazone itself but some other component in the product. This component may promote aberrant coagulation and so induce bleeding. There is no doubt that individual constitution is a key to the side effect, the same as allergic reactions. The failure of liver and renal function, advanced age, and malnutrition may be risk factors but there has been no exclusive evidence until now 
Table 1 Summary of cefoperazone or cefoperazone/sulbactam associated PT prolongation and bleeding from PubMed

\begin{tabular}{|c|c|c|c|c|c|c|}
\hline Author & Year & Drug & Case & No. PT $\uparrow$ & No. bleeding & Original disease \\
\hline Bailey et al. [2] & 1981 & $\mathrm{C}$ & 62 & 4 & 0 & Renal failure \\
\hline Cristiano [13] & 1984 & $\mathrm{C}$ & 1 & 1 & 0 & Acute renal failure \\
\hline Cohen et al. [1] & 1984 & $\mathrm{C}$ & 659 & 26 & 0 & Clinical trial \\
\hline Shimada et al. [24] & 1984 & $\mathrm{C}$ & 1 & 1 & 0 & Biliary tract infection \\
\hline Alitalo et al. [12] & 1985 & $\mathrm{C}$ & 3 & 3 & 3 & One renal failure \\
\hline Weitekamp et al. [25] & 1985 & $\mathrm{C}$ & 4 & 0 & 0 & Normal \\
\hline Shenkenberg et al. [26] & 1985 & $\mathrm{C}$ & 1 & 1 & 1 & Renal failure \\
\hline Andrassy et al. [8] & 1986 & $\mathrm{C}$ & 21 & 1 & 1 & Renal failure \\
\hline Freedy et al. [27] & 1986 & $\mathrm{C}$ & 3 & 3 & 3 & Cancer or bacteremia \\
\hline Jones et al. [28] & 1986 & $\mathrm{C}$ & 41 & 10 & 3 & Cancer \\
\hline Sattler et al. [20] & 1986 & $\mathrm{C}$ & 28 & 18 & 3 & Impaired renal function \\
\hline Strom et al. [14] & 1983-1986 & $\mathrm{C}$ & 374 & $45 / 366$ & $183 / 372$ & Multiple \\
\hline Guyot et al. [29] & 1987 & $\mathrm{C}$ & 30 & 1 & 1 & Biliary operation \\
\hline Greenberg et al. [4] & 1987 & $\mathrm{C} / \mathrm{S}$ & 70 & 2 & 1 & Urinary tract infection \\
\hline Muller et al. [30] & 1987 & $\mathrm{C}$ & 39 & 5 & 3 & Biliary tract infection \\
\hline Mueller et al. [23] & 1987 & $\mathrm{C}$ & 32 & 14 & 7 & Unspecific \\
\hline Mangi et al. [31] & 1988 & $\mathrm{C}$ & 68 & 12 & 0 & HAP \\
\hline Mortimer et al. [32] & 1988 & $\mathrm{C}$ & 88 & 0 & 0 & Febrile neutropenic \\
\hline Royer et al. [33] & 1988 & $\mathrm{C}$ & 2 & 2 & 0 & Acute renal insufficiency \\
\hline Jones et al. [34] & 1988 & $\mathrm{C}+\mathrm{K}$ & 53 & 15 & 3 & Cancer \\
\hline Pegram et al. [22] & 1989 & $\mathrm{C}$ & 130 & 6 & 3 & Febrile granulocytopenic \\
\hline Schäfer et al. [19] & 1989 & $\mathrm{C}$ & 5 & 2 & 0 & Urinary tract infection \\
\hline Winston et al. [35] & 1991 & $\mathrm{C}+\mathrm{K}$ & 138 & 0 & 0 & Febrile, granulocytopenic \\
\hline Rockoff et al. [21] & 1992 & $\mathrm{C}$ & 50 & 0 & 0 & Prophylactic use $3 \mathrm{~d}$ \\
\hline Li et al. [6] & 1993-1994 & $\mathrm{C} / \mathrm{S}$ & 103 & 0 & 0 & Respiratory and urinary infection \\
\hline Narumi et al. [36] & 1998 & $\mathrm{C}$ & 2 & 2 & 2 & $\mathrm{~TB}+$ bile duct cancer \\
\hline Alagozlu et al. [11] & 2006 & $\mathrm{C}$ & 1 & 1 & 0 & Choledocholithiasis \\
\hline Wong et al. [37] & 2006 & $\mathrm{C} / \mathrm{S}$ & 1 & 1 & 1 & Urinary tract infection \\
\hline Ozen et al. [38] & 2008 & $\mathrm{C}$ & 1 & 1 & 1 & Meckel's diverticulum \\
\hline Xin et al. [7] & 2005-2009 & $\mathrm{C} / \mathrm{S}$ & 141 & 0 & 0 & Respiratory and urinary infection \\
\hline
\end{tabular}

$C$ cefoperazone, $C+K$ cefoperazone + vitamin $\mathrm{K}, C / S$ cefoperazone/sulbactam, $H A P$ hospital acquired pneumonia, $P T$ prothrombin time, $T B$ tuberculosis, $3 d$ three days

[14]. The dosage and duration may not be associated with this side effect also [23].

\section{Conclusion}

This patient was misdiagnosed with incarceration of the abdominal hernia because the symptoms were quite similar to those of hernia. Unfortunately, it caused the clinicians to overlook the side effects of cefoperazone. Although no serious consequences were observed in this case, the warning it offers should be taken seriously. Cefoperazonerelated products can indeed cause vitamin K-dependent thrombin factor deficiency and hemorrhage, although the underlying mechanism is still not clear and the incidence is very low. Once abdominal pain, diarrhea, blood in the urine, hemoptysis, skin and mucosa petechia or ecchymosis, or hematoma appear, cefoperazone should be considered. Drug treatment should be stopped immediately, blood coagulation function should be checked, and supplemental vitamin $\mathrm{K}$ should be considered. This may prevent bleeding in high-risk patients.

Acknowledgments This work was supported by the Shanghai University of Traditional Chinese Medicine, "085" project (085ZY1216).

\section{Compliance with Ethical Standards}

Conflicts of interest ZhuYin Cai, Wei Yang, YingYing He, Qingge Chen, ShiQiang Wang, Xuming Luo and Xiongbiao Wang declare that they have no conflict of interest. 
Consent Written informed consent was obtained from the patient for publication of this case report and the accompanying images. A copy of the written consent may be requested for review from the corresponding author.

Open Access This article is distributed under the terms of the Creative Commons Attribution-NonCommercial 4.0 International License (http://creativecommons.org/licenses/by-nc/4.0/), which permits any noncommercial use, distribution, and reproduction in any medium, provided you give appropriate credit to the original author(s) and the source, provide a link to the Creative Commons license, and indicate if changes were made.

\section{References}

1. Cohen MS, Washton HE, Barranco SF. Multicenter clinical trial of cefoperazone sodium in the United States. Am J Med. 1984;77(1B):35-41.

2. Bailey RR, Peddie B, Blake E, Bishop V, Reddy J. Cefoperazone in the treatment of severe or complicated infections. Drugs. 1981;22(Suppl 1):76-86.

3. Drawz SM, Bonomo RA. Three decades of beta-lactamase inhibitors. Clin Microbiol Rev. 2010;23(1):160-201.

4. Greenberg RN, Reilly PM, Weinandt WJ, Bollinger M, Kennedy DJ. Cefoperazone-sulbactam combination in the treatment of urinary tract infections: efficacy, safety, and effects on coagulation. Clin Ther. 1987;10(1):52-6.

5. Koga H, Tomono K, Hirakata Y, Kohno S, Abe K, Kawamoto S, et al. Clinical evaluation of sulbactam/cefoperazone for lower respiratory tract infections. Correlation between the efficacy of sulbactam/cefoperazone and beta-lactamase. Jpn J Antibiot. 1996;49(8):800-7.

6. Li JT, Lu Y, Hou J, Chen YF, Miao JZ, Jia YX, et al. Sulbactam/ cefoperazone versus cefotaxime for the treatment of moderate-tosevere bacterial infections: results of a randomized, controlled clinical trial. Clin Infect Dis Off Publ Infect Dis Soc Am. 1997;24(3):498-505.

7. Xin X, Jian L, Xia X, Jia B, Huang W, Li C, et al. A multicentre clinical study on the injection of ceftriaxone/sulbactam compared with cefoperazone/sulbactam in the treatment of respiratory and urinary tract infections. Ann Clin Microbiol Antimicrob. 2013;12:38.

8. Andrassy K, Koderisch J, Fritz S, Bechtold H, Sonntag H. Alteration of hemostasis associated with cefoperazone treatment. Infection. 1986;14(1):27-31.

9. Islek I, Baris S, Katranci AO, Ariturk E, Gurses N. Hypersensitivity vasculitis induced by cefoperazone/sulbactam. Ann Clin Microbiol Antimicrob. 2003;3(2):1.

10. Mitra S, Basu S. Cefoperazone/sulbactam induced hyponatremia. Indian J Med Sci. 2006;60(4):158-9.

11. Alagozlu H, Cindoruk M, Unal S. Severe INR elevation in a patient with choledocholithiasis receiving cefoperazone. Clin Drug Investig. 2006;26(8):481-4.

12. Alitalo R, Ruutu M, Valtonen V, Lehtonen T, Pentikainen PJ. Hypoprothrombinaemia and bleeding during administration of cefamandole and cefoperazone. Report of three cases. Ann Clin Res. 1985;17(3):116-9.

13. Cristiano P. Hypoprothrombinemia associated with cefoperazone treatment. Drug Intell Clin Pharm. 1984;18(4):314-6.

14. Strom BL, Schinnar R, Gibson GA, Brennan PJ, Berlin JA. Risk of bleeding and hypoprothrombinaemia associated with NMTT side chain antibiotics: using cefoperazone as a test case. Pharmacoepidemiol Drug Saf. 1999;8(2):81-94.
15. Sattler FR, Weitekamp MR, Ballard JO. Potential for bleeding with the new beta-lactam antibiotics. Ann Intern Med. 1986;105(6):924-31.

16. Schentag JJ, Welage LS, Grasela TH, Adelman MH. Determinants of antibiotic-associated hypoprothrombinemia. Pharmacotherapy. 1987;7(3):80-6.

17. Allison PM, Mummah-Schendel LL, Kindberg CG, Harms CS, Bang NU, Suttie JW. Effects of a vitamin K-deficient diet and antibiotics in normal human volunteers. J Lab Clin Med. 1987;110(2):180-8.

18. Schentag JJ, Welage LS, Williams JS, Wilton JH, Adelman MH, Rigan D, et al. Kinetics and action of N-methylthiotetrazole in volunteers and patients. Population-based clinical comparisons of antibiotics with and without this moiety. Am J Surg. 1988;155(5A):40-4.

19. Schafer H, Naber K, Adam D. Hemostasis disturbance caused by cephalosporins with an $\mathrm{N}$-methylthiotetrazole side chain. A randomized pilot study. Arzneimittelforschung. 1989;39(9):115662.

20. Sattler FR, Colao DJ, Caputo GM, Schoolwerth AC. Cefoperazone for empiric therapy in patients with impaired renal function. Am J Med. 1986;81(2):229-36.

21. Rockoff SD, Blumenfrucht MJ, Irwin RJ Jr, Eng RH. Vitamin K supplementation during prophylactic use of cefoperazone in urologic surgery. Infection. 1992;20(3):146-8.

22. Pegram PS, Phair JP, McMahan R, Murphy RL, Gordon LI, Washton $\mathrm{H}$, et al. Prospective comparative trial of short course (four day) and continuous tobramycin in combination with cefoperazone or mezlocillin in febrile, granulocytopenic patients. J Antimicrob Chemother. 1989;24(4):591-604.

23. Mueller RJ, Green D, Phair JP. Hypoprothrombinemia associated with cefoperazone therapy. South Med J. 1987;80(11):1360-2.

24. Shimada K, Matsuda T, Inamatsu T, Urayama K. Bleeding secondary to vitamin $\mathrm{K}$ deficiency in patients receiving parenteral cephem antibiotics. J Antimicrob Chemother. 1984;14(Suppl B):325-30.

25. Weitekamp MR, Caputo GM, Al-Mondhiry HA, Aber RC. The effects of latamoxef, cefotaxime, and cefoperazone on platelet function and coagulation in normal volunteers. J Antimicrob Chemother. 1985;16(1):95-101.

26. Shenkenberg TD, Mackowiak PA, Smith JW. Coagulopathy and hemorrhage associated with cefoperazone therapy in a patient with renal failure. South Med J. 1985;78(4):488-9.

27. Freedy HR Jr, Cetnarowski AB, Lumish RM, Schafer FJ. Cefoperazone-induced coagulopathy. Drug Intell Clin Pharm. 1986;20(4):281-3.

28. Jones PG, Strother SV, Rolston KV, Fainstein V, Bodey GP. Hypoprothrombinemia in patients with cancer receiving cefoperazone and mezlocillin. Arch Intern Med. 1986;146(7):1397-9.

29. Guyot L, Allouch P, Fabre JP, Kazmierczak A. Prophylactic antibiotherapy in biliary surgery, cefazolin versus cefoperazone. Randomized comparative open study in a population at risk for infection. Pathologie-biologie. 1987;35(5):661-4.

30. Muller EL, Pitt HA, Thompson JE Jr, Doty JE, Mann LL, Manchester B. Antibiotics in infections of the biliary tract. Surg Gynecol Obstet. 1987;165(4):285-92.

31. Mangi RJ, Greco T, Ryan J, Thornton G, Andriole VT. Cefoperazone versus combination antibiotic therapy of hospital-acquired pneumonia. Am J Med. 1988;84(1):68-74.

32. Mortimer J, Miller S, Black D, Kwok K, Kirby WM. Comparison of cefoperazone and mezlocillin with imipenem as empiric therapy in febrile neutropenic cancer patients. Am J Med. 1988;85(1A):17-20.

33. Royer JM, Freysz M, Sgro C, Dupont G, Honnart D. Prolonged bleeding time in 2 patients with acute renal insufficiency during 
treatment with cefoperazone (2nd generation cephalosporin). Therapie. 1988;43(6):485-8.

34. Jones P, Bodey GP, Rolston K, Fainstein V, Riccardi S. Cefoperazone plus mezlocillin for empiric therapy of febrile cancer patients. Am J Med. 1988;85(1A):3-8.

35. Winston DJ, Ho WG, Bruckner DA, Champlin RE. Beta-lactam antibiotic therapy in febrile granulocytopenic patients. A randomized trial comparing cefoperazone plus piperacillin, ceftazidime plus piperacillin, and imipenem alone. Ann Intern Med. 1991;115(11):849-59.
36. Narumi S, Sasaki M, Okudera D, Tann E, Konn M. Postoperative abnormal prothrombinemia in patients with cefoperazone: report of two cases. Surg Today. 1998;28(2):227-30.

37. Wong RS, Cheng G, Chan NP, Wong WS, Ng MH. Use of cefoperazone still needs a caution for bleeding from induced vitamin K deficiency. Am J Hematol. 2006;81(1):76.

38. Ozen IO, Moralioglu S, Karabulut R, Bagbanci B, Turkyilmaz Z, Demirogullari B, et al. Cefoperazone induced gastro-intestinal haemorrhage. A case report. Acta Chirurgica Belgica. 2008;108(6):777-8. 